\title{
Rapideye Images in the Study of Contaminated Areas: The Case of Niccioleta (Tuscansy-Italy)
}

\author{
Teresa Balvis ${ }^{1}$, Francesco Muntoni ${ }^{2}$ and Roberto Rizzo ${ }^{2}$ \\ 1. GeoparcoS.c.a.r.l., Via delle miniere, snc Z.I. 09030 Elmas, Italy \\ 2. Consorzio del Parco Geominerario Storico Ambientale della Sardegna, Via Monteverdi 16 09016, Iglesias, Italy
}

\begin{abstract}
Mining activity in Italy has been one of the main productive activities for millennia, particularly in the Tuscany region which has a great mining tradition, unfortunately characterized in the past by a management little interest to environmental problems. The area under study is the disused mine Niccioleta, in Val d'Aspra, located about $6 \mathrm{~km} \mathrm{NE}$ of Massa Marittima in the province of Grosseto. The area is characterized by the presence of four major landfills, in which prevail quantitatively fine-grained materials resulting from the treatment by flotation of pyrite. The study of satellite images offers a new approach to the study of environmental problems. The results obtained from the RapidEye images showed the presence of pyrite and chalcopyrite followed from arsenopyrite, as confirmed by the analysis of diffractometer of the samples and by bibliographic data. RapidEye images lend themselves very to be used to monitor areas of disused mining deposits of ores with primary mineralization predominantly sulphides and subject to oxidized characterized by processes of oxidation/dissolution of pyrite sulphide most common and abundant. In fact, the results of this study have highlighted the potential of remote sensing applied to the study of mining areas, noting the possible benefits, both time and cost, which could be obtained by using these techniques.
\end{abstract}

Key words: Remote sensing, RapidEye, mining areas, heavy metals.

\section{Introduction}

Mining is one of the industrial activities that can generate a more significant impact on the environment causing substantial morphological and chemical modifications. The most significant impact is represented by the dispersion into the environment of toxic elements such as heavy metals (i.e., $\mathrm{Cu}, \mathrm{Pb}, \mathrm{Zn}$, $\mathrm{Cd}, \mathrm{Hg}, \mathrm{Cr}, \mathrm{Ni})$ [9-10]. The dispersion phenomena occur naturally; however, the human intervention through growing mining through parts of mineralization exposed, waste materials accumulated in the outer or as stuffed as well as sludge flotation stored in special reservoirs, greatly enhance the scope of the phenomenon. In the last three decades, the growing awareness of the need to combine productive activities and economic development, generally with the protection of the environment, has stimulated, especially in countries like USA, Canada and

Corresponding author: Teresa Balvis, Ph.D., research fields: remote sensing and study of mining areas.
Australia, numerous studies and initiatives aimed at understanding the mechanisms of dispersal and consequent mapping of toxic elements because of mining, in order to predict and prevent the consequences, and/or propose appropriate measures of containment and remediation [18]. In Italy this is a very sensitive issue, especially in a region like Tuscany, where there is a great mining tradition, unfortunately characterized in the past by a management little interest to environmental problems. The advent of new remote sensing techniques, in particular the study of satellite images, offers a new approach to the study of environmental problems. In fact, recent studies show that the analysis of remote sensing data is possible to obtain information useful for integrating mineralogical and geochemical data for the characterization of the mining areas, through the construction of maps of the distribution of various minerals [19]. This study aims to identify, by means of remote sensing techniques, the presence of minerals 
that determine the dispersal of toxic elements such as heavy metals. The work intends to characterize in an alternative and effective these polluted areas, supporting the characterization and remediation of contaminated mining sites, with an approach that increases the efficiency of the remediation process of the site, saving time and valuable resources.

\section{The Studied Area}

The study area is the abandoned mine of Niccioleta, in Val d'Aspra, located about $6 \mathrm{~km} \mathrm{NE}$ of Massa Marittima in the province of Grosseto. In this mine have been grown in the past pyrite, $\mathrm{Pb}-\mathrm{Zn}(\mathrm{Ag})$ sulfides, and $\mathrm{Fe}$ oxide and hydroxide mineralizations [2-4]. Polymetallic mineralizations have been the subject of mining, albeit with ups and downs, since the Etruscan period until the mid-twentieth century. Until 1992, the year of closure, the mining activity has affected only the pyrite mineralization, a mineral that was used for the production both sulfuric acid and iron pellets, with an industrial process that also included recovery of heat for energy purposes [16-17]. In this mine site there are four main landfills predominantly characterized by fine-grained material from the treatment by flotation. The maximum development of the mine is about three kilometers in NS direction and about 500 to $600 \mathrm{~m}$ in EO direction [22]. Currently the Niccioletamining area is part of the Parco Nazionale of Colline Metallifere of Grosseto-Tuscan Mining Geopark, and is subject to remediation with permanent safety (the process is still active) [21].

\section{Materials and Methods}

The images used for the study of the mining Niccioleta, are those of the sensor RapidEye, acquired on 10 June 2012. RapidEye is a constellation of five heliosynchronous satellites, aligned on the same orbit and perfectly identical, that allow the acquisition of images with a resolution of 5 meters and 5 multispectral bands, of vast areas, with a revisiting

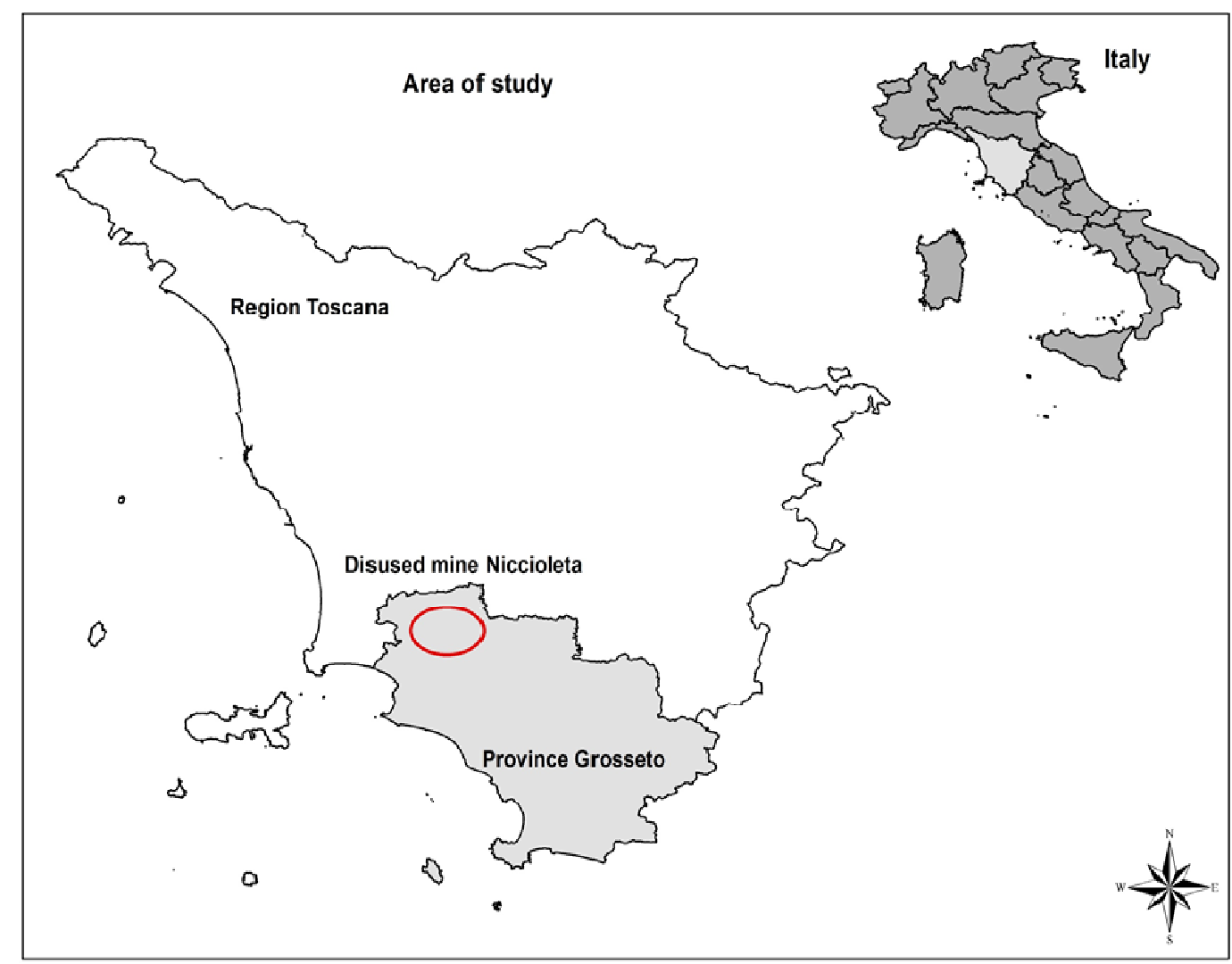

Fig. 1 Geographical framework area of the study. 
time very short (even daily). The bands used in this paper are those of the visible, of the near and mid-infrared, i.e., the spectral ranges used in geological-mineralogical studies. This spectral range of the VNIR, 0.440 to $0.850 \mu \mathrm{m}$ (bands 1-5), allows the identification of minerals in which are present the transition metals, particularly iron $[1,6,8]$.

RapidEye images have been provided already radiometrically corrected (Level Processing 1b) and orthorectified by using orbital model (Level Processing ORTHO).

The RapidEye image analysis was performed using the software Envi 4.8, widely used for this type of study.

RapidEye images were analyzed by the algorithm Vegetation Delineation, in the software, which after the atmospheric correction [13], quickly identifies the presence and/or absence of vegetation and calculates NDVI. This procedure attempts to identify in an immediate areas without vegetation and therefore to focus further analysis only in these areas. The next stage involved the spectral analysis of the image by classifying, using the SAM algorithm Spectral Angle Mapper associated with the "Library Niccioleta", with values of 0.5 . The spectral library was built starting from the spectral library USGS Mineral Spectral Library (splib04) [5-7]; from it were selected the minerals that it knew for sure from previous studies, be present in the investigated area. Then, the "Library Niccioleta" was resampled on the RapidEye data.

In order to confirm the analysis of the satellite data, they picked up some soil samples in order to determine the minerals present by analysis by X-ray diffraction. In reality this is not true of soils (i.e., characterized by the presence of at least one horizon rich in organic matter), but loose materials essentially of sterilized cultivation and treatment with very little or no soil formation processes. To each sample was taken the very top layer of the substrate, with a maximum depth of $1 \mathrm{~cm}$ from the surface. The samples of substrate were performed diffraction analysis, with the X-ray diffractometer (XRD PANalytical Xpert Pro) to determine the mineralogical composition. The identification of the peaks was performed automatically with the software supplied with the instrument.

\section{Results and Discussion}

The processed images (Fig. 4) show that the landfill areas have been subject to reclamation. In fact, these are partially vegetated; however, this has not prevented to highlight, in areas without vegetation, the presence of certain minerals that are formed consequently to the oxidation of pyrite.

The minerals, which is known to be present in the area, are also those that are most easily detectable in the bands of the RapidEye sensor. In fact, among the transition metals iron is one of the most important because its presence, either as ferrous ion $\left(\mathrm{Fe}^{2+}\right)$ both as a ferric ion $\left(\mathrm{Fe}^{3+}\right)$, allows a good spectral characterization of mafic minerals [11, 12, 14, 15].

The presence of iron in the minerals and rocks is highlighted in the respective spectral signatures by different absorption bands each linked to a specific type of transition. For the ferrous ion $\left(\mathrm{Fe}^{2+}\right)$, linked to oxygen ions, the most intense absorption band is 1.1 $\mu \mathrm{m}$, while large and less intense bands are in the infrared region at $0.43,0.45,0,51,0.55 \mu \mathrm{m}$ and in the infrared region near at 1.8 and $1.9 \mu \mathrm{m}$ [11]. These absorption bands are due to electronic transitions between the two groups of electronic levels in which the "d orbitals" separate in the field of octahedral coordination.

While the ferric ion $\left(\mathrm{Fe}^{3+}\right)$ presents little intense absorption bands at $0.40,0.45,0.49,0.70$ and $0.87 \mu \mathrm{m}$ [11]. The minerals that contain iron can be precisely distinguished because of these absorption bands.

To assess the reliability of the interpretation of spectral signatures, they were compared to results obtained from X-ray diffraction. In general, the results of XRD (X-ray diffraction analysis) show in most of the examined samples the presence of pyrite, 


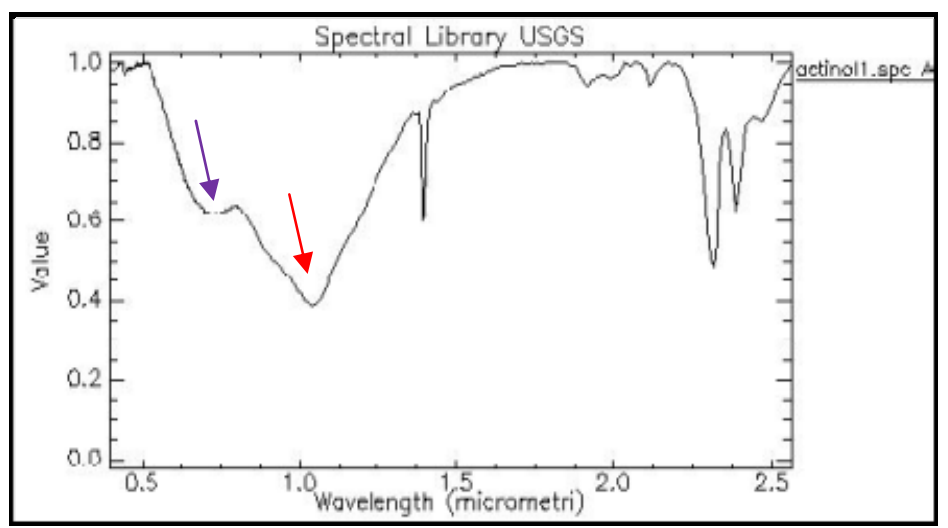

Fig. 2 Signature spectral dell'actinolite, extracted from the USGS spectral library Mineral Spectral Library (splib04)-Example nell'anfibolo (actinolite) the absorption band close to $1 \mu \mathrm{m}$ is indicative of the content of ferrous ions $\left(\mathrm{Fe}^{2+}\right)$, while the nearest to $0.7 \mu \mathrm{m}$ is linked to the presence of ferric ions $\left(\mathrm{Fe}^{3+}\right)$.

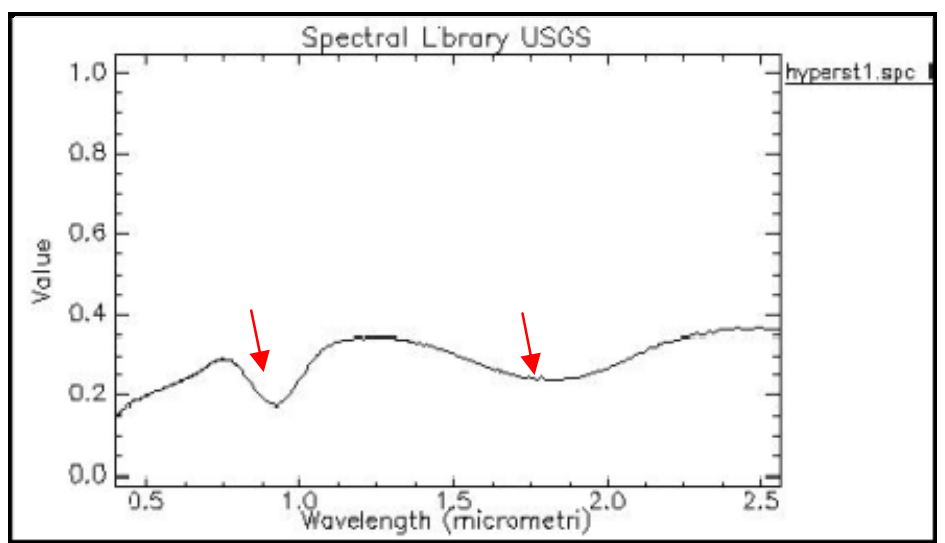

Fig. 3 Spectral signature iperstene, extracted from the USGS spectral library mineral spectral library (splib04)-In the spectral signature of pyroxene (iperstene), ferrous ion $\left(\mathrm{Fe}^{2+}\right)$ determines a strong absorption near $0.9 \mu \mathrm{m}$ and a milder 1.8 $\mu \mathbf{m}$.

chalcopyrite and arsenopyrite as the major minerals; they are also present minerals such as goethite, hematite and/or illite. These data are in agreement with previous studies on the area and with the results of the analysis of the images RapidEye. However some inconsistencies were found between the analysis with the diffractometer and the spectral analysis of the image, due to inherent limitations of determining the spectral signature of an area in a natural system, on which many factors that can not be quantified, such as the conditions of acquisitions of the data and the size distribution of the particles.

\section{Conclusions}

With this work we wanted to contribute to the development of methodologies useful to the investigation of pollution phenomena in mining areas with an approach that integrates knowledge mineralogical with new remote sensing data, such as RapidEye images. The obtained results highlighted the potential of the remote sensing applied to the study of mining areas, noting the possible benefits, of both time and costs, which could be obtained using these techniques.

RapidEye images lend themselves very to be used to monitor abandoned mining areas of metal ore deposits with prevalent primary sulfides mineralization and subordinately oxidized. Since the sulfides are generally unstable in the supergenic environment, the exogenic exposure of the ore bodies causes their oxidation and/or dissolution, with consequent release of the metals contained [20]. One of the main products 

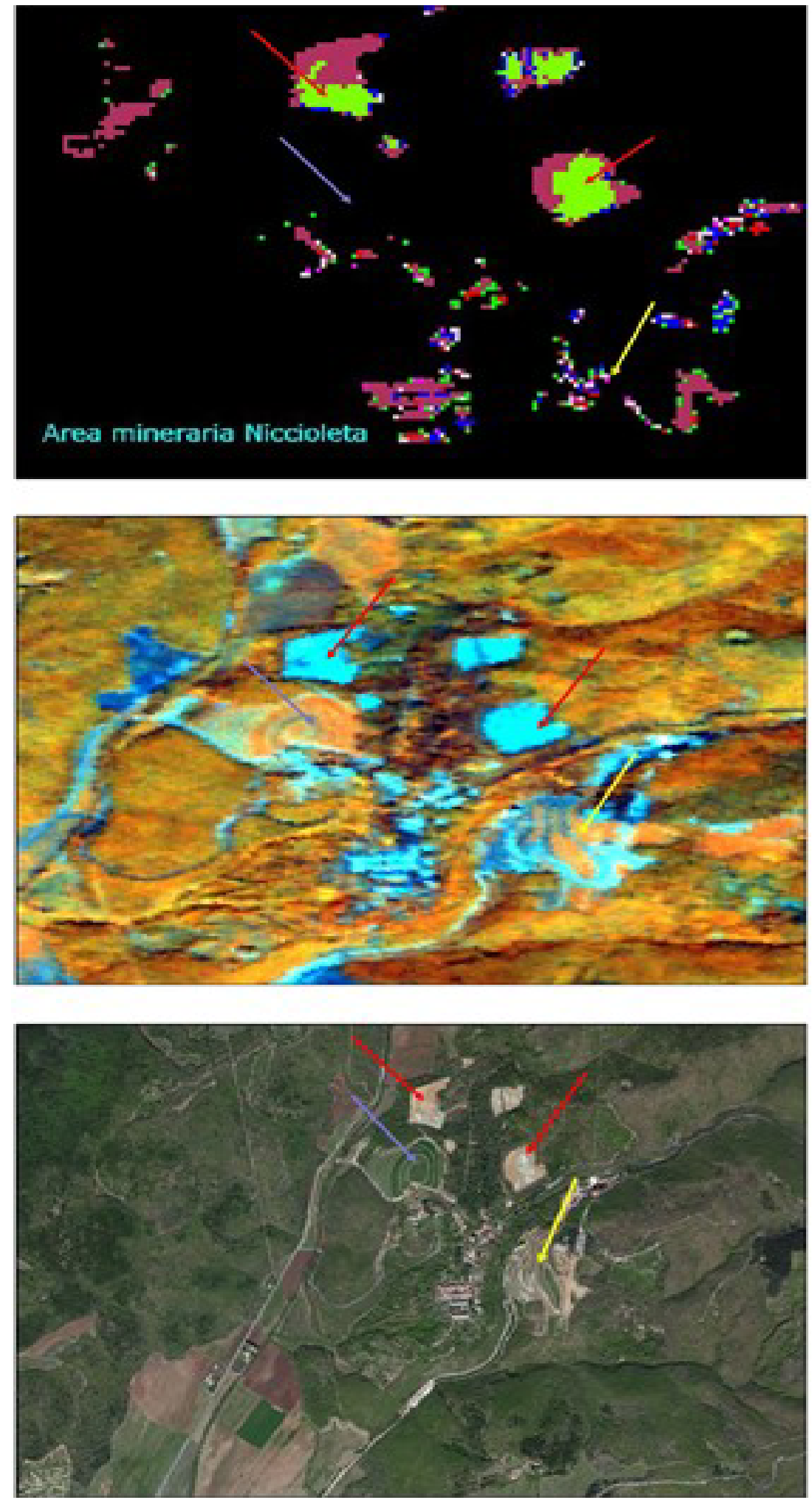

Fig. 4 Niccioleta mining area. Comparison between the combinations of the RapidEye_543 images and the orthophoto: the red arrows indicate areas of landfill under remediation where you can still identify the present minerals. The violet arrows indicate the areas already remediated, largely covered with vegetation where it is not possible to identify any mineral phase. Finally, the yellow arrows indicate the remediated areas but not completely vegetated where it is possible to identify some mineral phases. 


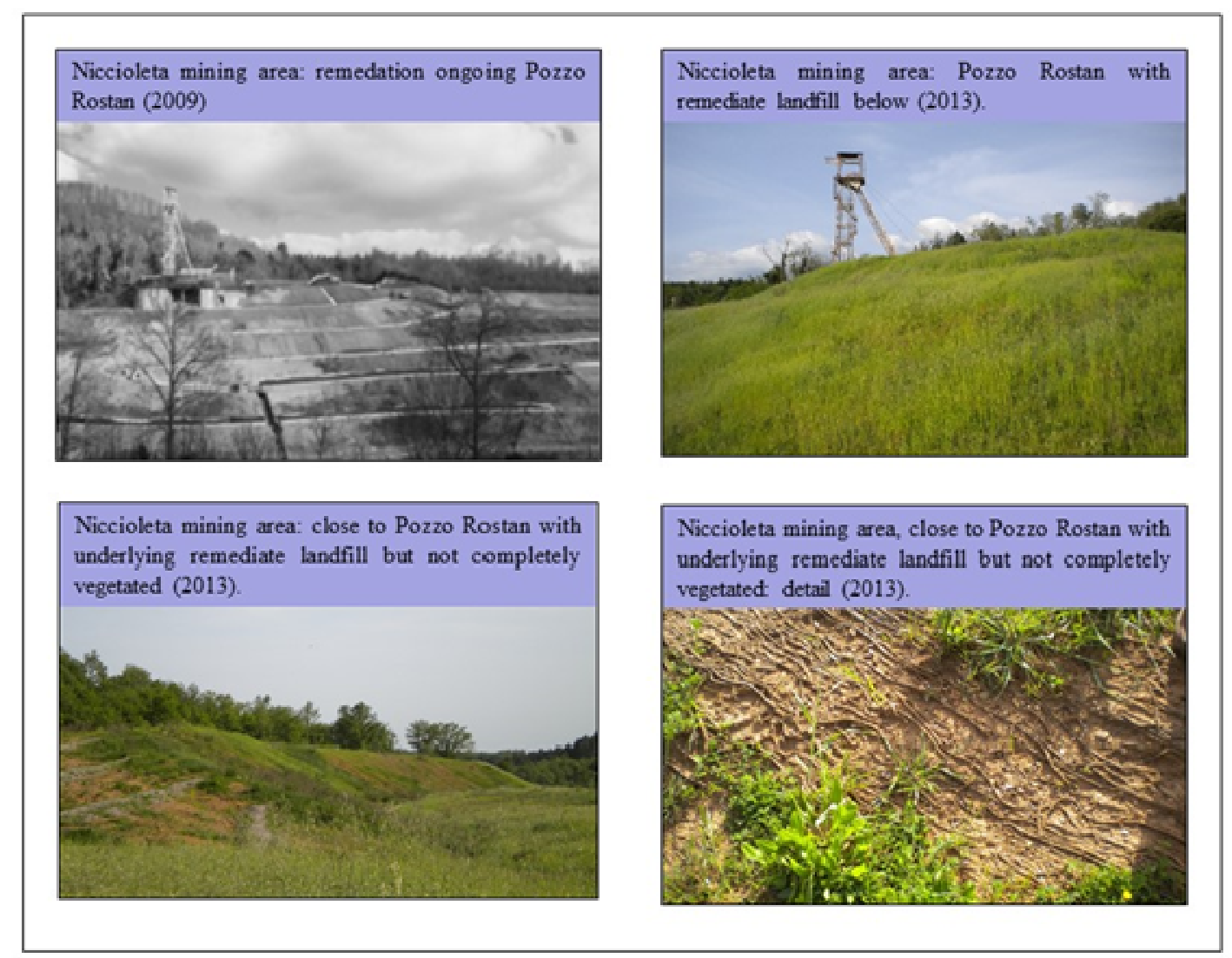

Fig. 5 Niccioleta mining area: close to Pozzo Rostan.

of these reactions is iron: its presence, both as ferrous $\left(\mathrm{Fe}^{2+}\right)$ and ferric ion $\left(\mathrm{Fe}^{3+}\right)$, provides good spectral characterization of the mafic minerals. The minerals that contain iron can be therefore easily distinguished by virtue of the specific absorption bands. The RapidEye images help identify these minerals: their use, therefore, given also the considerable spatial resolution $(5 \mathrm{~m})$, it lends itself very well to monitor the disused mining areas characterized by processes of oxidation/dissolution of pyrite, the most common and abundant sulfide.

Better results may be obtained with an increase of mineralogical analysis; it will be possible to have a complete mapping of the environmental status of the mining area.

\section{Acknowledgements}

We thank Dr. Fabiano Field for RapidEye images kindly provided by IptSat and Dr. Alessandra Casini director of the Consortium of the National Park of the
Colline Metallifere Grossetane to the guided tours in the studied area.

\section{References}

[1] Altinbas, U., Kurucu, Y., and Bolca, M. 2005. "Using Advanced Spectral Analyses Techniques as Possible Means of Identifying Clay Minerals." Turk Journal Agric. 29.

[2] Brizzi, G., Capperi, M., and Casotti, A. 1989. "La miniera di pirite di Niccioleta, Massa Marittima (GR) 1a parte." Rivista mineralogica italiana 4.

[3] Brizzi, G., Capperi, M., and Casotti, A. 1990. "La miniera di pirite di Niccioleta, Massa Marittima (GR) 2a parte." Rivista mineralogica italiana 1.

[4] Brizzi, G., Capperi, M., and Casotti, A. 1990. "La miniera di pirite di Niccioleta, Massa Marittima (GR) 3a parte." Rivista mineralogica italiana 2.

[5] Clark, R. N., Swayze, G. A., Wise, R., Livio, K. E., Hoefen, T. M., Kokaly, R. F., and Sutley, S. J. 2007. "USGS Digital Spectral Library splib06a." $U$. S. Geological Survey Data Series 231. 20 September. http://speclab.cr.usgs.gov/spectral.lib06.

[6] Clark, R. N., Boardman, J., Mustard, J., Kruse, F., Ong, C., Pieters, C., and Swayze, G. A. 2006. "Mineral 
Mapping and Applications of Imaging Spectroscopy.” Presented at IGARSS 2006, Denver, Colorado.

[7] Clark, R. N., Swayze, G. A., Wise, R., Livo, K. E., Hoefen, T. M., Kokaly, R. F., and Sutley, S. J. 2003. USGS Digital Spectral Library splib05a. U.S. Geological Survey, Open File Report 03-395.

[8] Clark, R. N. 1999. "Spectroscopy of Rocks and Minerals, and Principles of Spectroscopy." In Manual of Remote Sensing, edited by Rencz, A.N. Vol. 3. New York: John Wiley and Sons.

[9] Fanfani, L., Caboi, R., Cidu, R., Cristini, A., Frau, F., Lattanzi, P., and Zuddas P. 2001. "Impatto ambientale dell'attività mineraria in Sardegna: studi mineralogici e geochimici." Rend. Semin. Fac. Sci. Univ. Cagliari 70 (suppl.): 249-64.

[10] Fanfani, L. 1996. Mobilizzazione di Metalli Pesanti Nelle Aree Minerarie Abbandonate. Quaderni di Geologia Applicata 4 suppl.

[11] Grove, C. I., Hook, S. J., and Paylor, E. D. 1992. Laboratory Reflectance Spectra for 160 Minerals 0.4-2.5 Micrometers: JPL Publication 92-2. Jet propulsion Laboratory, Pasadina, California.

[12] Hubbard, B. E., Crowley, J. K., and Zimbelman, D. R., 2003. "Comparative Alteration Mineral Mapping Using Visible to Shortwave Infrared (0.4-2.4 $\mu \mathrm{m})$ Hyperion, Ali and Aster Imagery." IEEE Transactions on Geoscience and Remote Sensing 41 (6).

[13] Kruse, F. A. 2004. "Comparison of ATREM, ARCON, and FLAASH Atmospheric Corrections Using Low-Altitudine Aviris Data of Boulder." In Proceedings of 13th JPL Airborne Geoscience Workshop, Mar. 31-Apr. 2, Pasadena, CA.

[14] Kruse, F. A. 1998. "Advances in Hyperspectral Remote Sensing for Geologic Mapping and Exploration." Presentato al $9^{\circ}$ Australian Remote Sensing Conference, Sydeny, Australia.
[15] Kruse, F. A. 1997. "Characterization of Active Hot-Springs Enveroniments Using Multispectral and Hyperspectral Remote Sensing." Presentato al Twelfth International Conference and Workshops on Applied Geologic Remote Sensing, Denver, Colorado.

[16] Lattanzi, P., and Tanelli, G. 1978. "Considerazioni Genetiche Sulla Cotunnite Del Giacimento a Pirite di Niccioleta (Toscana)." RENDICONTI Società Italiana di Mineralogia e Petrologia 34 (1): 37-44.

[17] Lattanzi, P., and Tanelli, G. 1985. "La Mineralizzazione a Pirite, a Ossidi di Fe e Pb-Zn (Ag) Nella Zona di Niccioleta (Grosseto).” RENDICONTI Società Italiana di Mineralogia e Petrologia 40: 385-408.

[18] Montero, I. C., Brimhall, G. H., Alpers, C. N., and Swayze, G. A. 2005. "Characterization of Waste Rock Associated With Acid Drainage at the Penn Mine, California, by Ground-Based Visible to Short-Wave Infrared Reflectance Spectroscopy Assisted By Digital Mapping." Chemical Geology 215.

[19] Montero, I. C., and Brimhall, G. H. 2001. "Semi-automated Mineral Identification Algorithm for Ultraviolet, Visible and Near Infrared Reflectance Spectroscopy." Presentato al Annual Conference of the International Association for Mathematical Geology. IAMG, Kansas.

[20] Plumlee, G. S. 1999. "The Environmental Geology of Mineral Deposits." In Reviews in Economic Geology. Vol. 6A. Part A: Processes, Techniques and Health Issues.

[21] Preite, M. 2009. MASTERPLAN: La valorizzazione del paesaggio minerario. Parco Nazionale Tecnologico e Archeologico delle Colline Metallifere Grossetane, Edizioni Polistampa RSI: Research Systems Inc.

[22] Tesser, E. 2012. Monitoraggio e Trattamento di Drenaggi di Miniera Mediante Filtrazione Lenta, Università degli Studi della Basilicata, Tesi di Dottorato di Ricerca in Metodi e Tecnologie per il Monitoraggio Ambientale. 